\title{
History of Neurosurgery in India $\ldots$
}

\author{
Atul H. Goel, M.Ch., and Trimurti D. Nadkarni, M.Ch. \\ Department of Neurosurgery, King Edward Memorial Hospital, Seth G. S. Medical College
}

A brief history of the development of neurosurgery in India is presented. References to neurosurgery can be found in the ancient Indian medical texts: Neurosurgery emerged as an independent speciality in India since the 1940 's evolving with the independence of the country. The development of neurosurgery in various parts of the country is outlined. The Neurological Society of India is the national society for neuroscientists. Neurology India is the official journal of the society. Pioneering contributions have been made by Indian neurosurgeons. The present state of neurosurgery and neurosurgical training in India has been enumerated.

(Received October 8, 2004; accepted November 2, 2004)

Key words : neurosurgery, history

Jpn J Neurosurg（Tokyo）14:69-73, 2005

\section{Introduction}

The development of Neurosurgery in India during the past 55 years has almost paralleled the achievements of the country in its " 55 years of freedom". There were neither trained neurosurgeons nor any departments of neurosurgery at the time of independence in 1947. A few general surgeons were performing neurosurgery at that time. All heads of surgical, medical and basic science departments considered neurosurgery, neurology and its ancillariesneuroradiology, neuropathology, neurophysiology and neurochemistry irrelevant under the circumstances. It was a continuos struggle to get rid of this controlling yoke.

Over the years, there has been a tremendous change. Neurosurgically treatable diseases are now diagnosed and referred in good time. Many ancillary diagnostic facilities are now available, and even the patients themselves are aware of the need to seek early neurological consultation. Neurosurgery in India is now on a par with the best services available in the world. All necessary technological advances as well as qualified personnel are available in the country. Though the centers of excellence are based in the major metropolises of the nation, access to these services is easier than before. Assimilation and application of technological advances has been at such a rapid rate that many centers are on a par with similar counterparts abroad.

\section{Neurosurgery in Ancient Medical Literature ${ }^{5)}$}

The principal authors of the ancient Indian medical text were Susruta, Charaka, Vagavata, Vela and Madhava. Ancient Indian medical scientists were uncertain whether Hridaya (heart) or mastishka (brain) was the seat of consciousness. The word mastishka and mastulunga (brain) appears in the Charaka and Susruta Samahitas. An account of the central nervous system and its pathologies occurs in these texts.

Tracing the development of neurosurgery in ancient India, the following salient references are found. The transplantation of the head of an elephant on Ganesha (an Indian Diety), trepanantion and removal of an intracranial mass by Jivaka (physician to the Lord Buddha) and the neurosurgical accomplishments of Sushruta, the master surgeon,

Address for correspondence: Professor Atul Goel, Head, Department of Neurosurgery, King Edward Memorial Hospital, Seth G. S. Medical College 
are all documented in the Susruta Samhita.

\section{Early Pioneers of Neurosurgery in India ${ }^{3) 6 \text { ) }}$}

Drs. A. P. Bacha, G. V. Deshmukh, R. N. Cooper, A. V. Baliga in Bombay; N. S. Narasimhan, C. V. Vishwanatha Menon and U. Mohan Rao in Madras ; Lt. Col. F. J. Anderson and Provat Sanyal in Calcutta, Col. R. Mirajkar and Baldev Singh at Lahore and Balkrishna Rao of Mysore were the pioneers of Neurosurgery in India.

\section{Emergence of Neurosurgery as an Independent Speciality ${ }^{3 / 6)}$}

Although neurosurgery was being performed with gradually increasing interest by general surgeons in Bombay since 1940, the credit for starting it as an independent speciality goes to Dr. Jacob Chandy of Vellore who after completing his training in Canada and the United States, started a separate department at the Christian Medical College and Hospital, Vellore in the second quarter of the year 1949 with 12 beds spread throughout the various medical and surgical wards.

Dr. B Ramamurthy soon followed at the Government General Hospital in Madras in the fall of the same year. He had to work as a General Surgeon till a separate and independent chair for neurosurgery was created in the year 1950. Dr. S. T. Narasimhan started a private neurosurgical clinic in Madras in the year 1948 and later set up an EEG laboratory at the Government General Hospital, Madras in the year 1950 .

Dr. Ram G. Ginde started the first specialized department of neurosuregry, and the third in the country, at the Seth G. S. Medical College and King Edward Memorial Hospital in April, 1951. Initially Ginde's patients were housed in a general surgery ward. He carried out all neuroradiological tests himself and performed 2-3 operations every week. More than 80 per cent of the allotted 25 beds were occupied by neurosurgical cases within the first six months. After considerable struggle, a separate and independent department of neurology and neurosurgery was opened in the fall of 1953.

With only three qualified neurosurgeons for the entire country till $1956-57$, the workload at all these centers rap- idly increased both in quality and in quantity.

\section{Development of Neurosurgery in Differ- ent Parts of the Country ${ }^{3) 6}$ )}

Most of the pioneers of neurosurgery were trained in the west, predominantly in England and the United States. Some of these doctors persevered in their attempts to set up neurosurgical services; however some lost their patience and returned to greener pastures abroad.

\section{1] In South India}

At the CMC and Hospital, Vellore, the first neurosurgical department started in April-May 1949 with the appointment of Dr. Jacob Chandy as Associate Professor of Neurosurgery. He became Professor in 1954. In the earlier years, he had as his close associate, Dr. Baldev Singh, a neurologist. It was here, that the first Residency Training program was started in 1954 . The first recognized University course for M.S and later for M.Ch. was begun in 1958. Dr. K. V. Mathai was the first person to have undertaken his entire training and to qualify as a neurosurgeon in India. The first Neurology Training Programme was initiated in 1966 .

Dr. B. Ramamurthi, in Madras, made similar headway at the Madras Medical College and Governmenat General Hospital. The Institute of Neurology was later established here in 1965. The other centers of note were Stanley Medical College, Madras in 1962 under Dr. P. Narendran and at Madurai in 1963 under Dr. M. Natrajan. The late Govinda Swami established the All India Institute of Mental Health at Bangalore in the early 1950's. Dr. R. N. Verma started a formal neurosurgical department in a mental hospital in 1959. This was later to form the National Institute of Mental Health and Neurosciences. In Kerala, the first neurosurgical unit was started at Trivandrum in 1966 with Dr. Bahuleyan and Dr. Sambasivan and another at Calicut with Dr. Rajan in 1969.

\section{In West India}

Regular neurosurgery was started in Mumbai in January, 1951 at the Seth Gordhandas Sunderdas Medical College and King Edward VII Memorial Hospital. However, it was not until October, 1953 that the Department of Neurology and Neurosurgery was at last opened after a consider- 
able struggle with a separate ward of 40 beds and an independent operation theater. Dr. Homi Dastur, Dr. U.S. Vengsarkar, and later, Dr. Sunil K Pandya worked in the unit.

At the Grant Medical College and the Sir Jamsetjee Jejeebhoy Group of Hospitals, one of the three oldest medical colleges in the country, a separate neurosurgery unit was started in 1959. Professor of Surgery, Shantilal J. Mehta, encouraged Gajendra Sinh, to train in neurosurgery at Vellore, who then headed this unit. Dr. S. N. Bhagwati and Dr. V.S. Dave later joined this unit.

At Topiwala National Medical College, Dr. S. Patrao a senior honorary general surgeon had started operating occasionally for lumbar discs, spinal cord tumors and tics in the early fifties. Dr. V. G. Daftary later joined him. In 1971 a formal department of neurosurgery was established. Dr. B. J. Damany and Dr. P. S. Ramani set up the Department of Neurosurgery in Lokmanya Tilak Medical College and Hospital, Sion in 1975.

Neurosurgical work for private patients in Mumbai was started at the Bacha Memorial Nursing Home and Parsee General Hospital in 1951, thereafter at the Breach Candy and the Bombay Hospitals in 1954.

In Poona, Dr. R. D. Variava was practicing neurosurgery since 1966. Dr. S. D. Dighe followed him soon thereafter. Col. Virendra Mohan at the Armed Forces Medical College, Dr. Azariah in Miraj, and Dr. N. A. Siddiqui at Nagpur were the pioneers of neurosurgery in these cities.

In Ahmedabad, the services were started under P. R. Thakore at the Civil Hospital. The first Department of Neurosurgery was however opened at the Sheth Vadilal Sarabhai Hospital in 1963 by Dr. B. J. Damany.

\section{In North India}

Neurology and neurosurgery started in 1956 with the arrival of Baldev Singh from Vellore, at the Tirath Ram Shah Charitable Hospital. Dr. Victor M. Rao started regular neurosurgical work in the year 1958-59. In 1962-63, a second neurosurgical unit came into being at the G B Pant Hospital, Delhi with Arjun Sehgal as neurosurgeon.

The All India Institute of Medical Sciences was founded in 1946-47. The regular departments of neurology and neurosurgery came into existence only in March 1965 with the appointment of Dr. Baldev Singh as Professor of
Neurology and Dr. P.N. Tandon as Professor of Neurosurgery,

Another neurosurgery unit came into existence at the Safdarjung Hospital, New Delhi in 1967 under Dr. H. S. Ahaluwalia. A unit in the Military Hospital in New Delhi with Major R.S. Rana at the helm followed this.

Other centers in the northern region were as follows: at Lucknow in the period from 1958-61 at the Military Hospital under Lt. Col. A C Ray. D. R. Gulati in 1962 at the Post Graduate Institute of Medicine and Research, Chandigarh; Christian Medical College and Hospital, Ludhiana under Dr. Namboodripad ; Dr. M. G. Sarin at SMS Hospital, Jaipur in 1961-62; Banaras Hindu University in 1963 under Dr. S. K. Mukherjee.

\section{In East India}

In 1955, Herbert Krause of Vienna came to Calcutta at the invitation of B. C. Roy, the Chief Minister of the Government of West Bengal and set up neurosurgery at the S. S. K. M. Hospital. Dr. R. N. Chatterjee and Dr. Asoke Bagchi trained under him.

A center was started at Ranchi, Bihar under Dr. R. Prasad and Dr. Jaiswal and at Bhubaneshwar, Orissa by Dr. Sanathan Rath.

\section{In Central India}

The first neurosurgical unit in this region was started at the King George Hospital at Vizag (now Vishakapattanam) in 1956 by Dr. S. Balaparmeshwara Rao. Dr. B. Dayanand Rao started a unit at the Osmania Medical College and Hospital at Hyderabad in 1957. Units were also started at Kurnool under Dr. K. V. Chalapathy Rao in 1964-67 and at Guntur Medical College with Dr. M. V. Subramaniam.

\section{The Birth of Neurological Society of India ${ }^{16)}$}

In 1950, four full-time neuroscientists met in the city of Madras. Two neurosurgeons-Drs B. Ramamurthi and Mathew Chandy, one neurologist Dr. Baldev Singh and one clinical neurophysiologist Dr. S. T. Narasimhan. As a result of this meeting, the neurological society of India was inaugurated in the year 1951 at Hyderabad along with the annual meeting of the Association of Physicians of India. The four charter principles of the Society were as follows: 
1. All branches of the neurological sciences shall keep together as a united body as long as possible for their own development, which have close linkage and so shall be supporting each other.

2. Full members of the Society shall be only full time career workers in any of the neurological science disciplines.

3 . The Society shall always strive for excellence in its disciplines.

4. Competence shall be the hallmark of the clinical sections' of their neurological sciences.

\section{Neurology India ${ }^{1 / 6)}$}

Neurology India is the scientific publication of the Neurological Society of India launched in 1953. Dr. B. Ramamurthi was its first editor. He has been followed by $\mathrm{R}$. G. Ginde, A. Desai, P. N. Tandon, A. K. Bagchi, S. Kalyanraman, J. S. Chopra and S. Prabhakar. Professor Atul Goel is its present editor. This quarterly journal devoted to the Neurosciences is indexed with many databases including Medline/Index Medicus and the Citation Index.

\section{Indian Contributions to Neurosurgery ${ }^{4) 6)}$}

Pioneering work has been done by Indian neurosurgeons in the following fields: Craniovertebral anomalies, encephalocoeles, tuberculous meningitis, tuberculomas, anti-tuberculous therapy for intracranial tuberculous disease, parasitic infections, stereotactic surgery and fluorosis. Research activities have been conducted in the above fields.

\section{Neurosurgical Residency Training ${ }^{3 / 6)}$}

The first neurosurgical training center in India was at the Christian Medical College, Vellore. The Madras Medical College followed soon after. Since then, training centers in Neurosurgery have been set up in most other states. Many have obtained the coveted Master's qualification in Neurosurgery and have spread out to render excellent service to the pubic in various parts of India.

The Vice Chancellor of the Madras University Padmavibhushan Sir Lakshmanaswami Mudaliar was a very dynamic, progressive medical educator. He championed the concept of postgraduate degrees in the higher specialties in medicine and the concept of residency programs in training. It is noteworthy that to maintain high standards, the University of Madras enacted a regulation insisting that each candidate appearing for the examination leading to an M.Ch. in Neurosurgery performs an actual operation under the responsibility and supervision of the Professor of Neurosurgery at the Institution. This criteria has since been adopted at all other neurosurgery centers in the country.

Neurosurgery residency programs are available for three years after postgraduation in General surgery (M. S.) or a direct five years course after medical graduation (M. B., B. S.).

The Diplomate of National Board (D. N. B.) is awarded by the National Board of Examiners, New Delhi. Students work in recognized departments under the guidance of recognized teachers.

\section{The Present ${ }^{2) 6)}$}

During the last 30 years the number of neurosurgery centers has increased from the original three centers at Vellore, Madras and Mumbai to many units distributed throughout different parts of the country. Many of these units are adequately equipped to enable basic neuroradiological investigations and to cope with a variety of neurological and neurosurgical problems. They are adequately staffed with medical and paramedical personnel to ensure that timely and efficient treatment is given to serious and emergency cases at short notice and to provide proper aftercare and follow-up. There is proper record keeping, satisfactory secretarial assistance, and a good reference library with sufficient books and periodicals. There is a continuous well-organized in-service graduate training program for candidates who are selected after proper screening. This covers the theorectical aspects in the main and allied subjects and ensures a very satisfactory practical approach to clinical neurology and familiarity with bedside, diagnostic and operative procedures. There are regular bedside ward rounds, seminars, group discussions and actual performance of technical and diagnostic procedures including different types of operations under the supervision and guidance of the senior members of the staff. A dissertation or thesis, entailing a more detailed study in one 
of the aspects of the specialty is compulsory.

Today we have at least 15 centers of excellence where skull base surgery, vascular surgery, neuroendoscopy, radiosurgery, interventional neuroradiology, complex spinal instrumentation, deep brain stimulation and every conceivable type of neurosurgical procedure is carried out. We have a national Brain Research Center. We offer teleconsultation in neurosurgery to remote villages through satellites orbiting in outer space, which the Department of Space, Government of India has indigenously made and launched. There are only seven countries in the world, which have this capability. There are 800 neurosurgeons, 110 neurosurgical trainees, 55 residency programmes (5 National Institutes, 4 Deemed Universities, 25 Medical Colleges, 21 corporate, private and trust Hospitals) and 90 of 160 medical colleges with neurosurgical departments, neurosurgery units in 45 out of 275 corporate hospitals and about 125 small to medium nursing homes where basic neurosurgery is done. This is no doubt insufficient for one sixth of humanity. Many Government Hospitals in India provide the most complex neurosurgical services free of $\operatorname{cost}^{2)}$.

There are well qualified, skilled and experienced surgeons in the country but the conditions of their work in most institutions are deplorably poor. It is extremely ignorant, insultingly cynical and most unfair to expect good results from even well trained men and women under the present existing conditions. The trend is towards highly qualified Indians prefering to settle down abroad after their training or for those that have returned and seen the conditions of work tobe forced to leave the country for want of gainful employment and due to lack of adequate facilities in many ill-equipped Institutions. One often hears or reads about the national brain drain. However, this situation appears to be changing with the winds of globalization. Smaller towns have yet to have the services of a qualified neurosurgeon. Neurotrauma is still to be adequately treated at the peripheral, distant villages of our country. It is necessary, or rather essential, that large scale assistance should be made available by the Central and State Governments, philanthropic institutions and trusts, people in affluent circumstances and that the talents of the scientists and technocrats be harnessed for improving the standard of medical care, medical education and research.

It is gratifying to note that from a humble beginning at Vellore, Madras, and Bombay between 1949 and 1954, the country has now a multitude of neurosurgical services. Yet the total number of neurosurgeons is grossly inadequate even to provide uniform minimum basic neurosurgical services and facilities. It is expected that this shortfall will soon be overcome.

\section{References}

1) Chandy J: A struggle to conquer. In : Pandya SK (ed) : Neurosciences In India-Retrospect and Prospect. New Delhi, The Neurological Society of India, Trivandrum and Council of Scientific and Industrial Research, 1989, pp.1-4.

2) Ganapathy K: Point counterpoint. Newsletter of Neurological Society of India, Chennai III (2), 2002, pp.9-12.

3) Ginde RG: Neurosurgery in India. In : Pandya SK (ed) : Neurosciences In India-Retrospect and Prospect. New Delhi, The Neurological Society of India, Trivandrum and Council of Scientific and Industrial Research, 1989, pp.559576.

4) Kak VK: Neurosurgery. In : Pandya SK (ed) : Neurosciences In India-Retrospect and Prospect. New Delhi, The Neurological Society of India, Trivandrum and Council of Scientific and Industrial Research, 1989, pp.577-639.

5) Karapurkar A, Pandya SK : Neurosurgery in India. Neurosurg Rev 6:85-92, 1983.

6) Nadkarni TD, Goel A, Pandya SK: Neurosurgery in India. J Postgrad Med 48:332-335, 2002. 